\title{
A gold-containing drug against parasitic polyamine metabolism: the X-ray structure of trypanothione reductase from Leishmania infantum in complex with auranofin reveals a dual mechanism of enzyme inhibition
}

\author{
Andrea Ilari · Paola Baiocco · Luigi Messori • \\ Annarita Fiorillo • Alberto Boffi • Marina Gramiccia • \\ Trentina Di Muccio • Gianni Colotti \\ Received: 23 February 2011/Accepted: 7 April 2011/Published online: 11 August 2011 \\ (C) Springer-Verlag 2011
}

\begin{abstract}
Auranofin is a gold(I)-containing drug in clinical use as an antiarthritic agent. Recent studies showed that auranofin manifests interesting antiparasitic actions very likely arising from inhibition of parasitic enzymes involved in the control of the redox metabolism. Trypanothione reductase is a key enzyme of Leishmania infantum polyamine-dependent redox metabolism, and a validated target for antileishmanial drugs. As trypanothione reductase contains a dithiol motif at its active site and gold(I) compounds are known to be highly thiophilic, we explored whether auranofin might behave as an effective enzyme inhibitor and as a potential antileishmanial agent. Notably, enzymatic assays revealed that auranofin causes indeed a pronounced enzyme inhibition. To gain a deeper insight into the molecular basis of enzyme inhibition, crystals of the auranofin-bound enzyme, in the presence of NADPH, were prepared, and the X-ray crystal structure of
\end{abstract}

A. Ilari and P. Baiocco contributed equally to the work.

A. Ilari $(\bowtie) \cdot$ P. Baiocco · A. Fiorillo · A. Boffi ·

G. Colotti $(\square)$

Department of Biochemical Sciences, Institute of Molecular

Biology and Pathology CNR, Sapienza University of Rome,

P.le A. Moro 5, 00185 Rome, Italy

e-mail: Andrea.ilari@uniroma1.it

G. Colotti

e-mail: Gianni.colotti@uniroma1.it

L. Messori

Department of Chemistry, University of Florence,

Via della Lastruccia 3, 50019 Sesto Fiorentino, Florence, Italy

M. Gramiccia - T. Di Muccio

Dipartimento di Malattie Infettive, Parassitarie e

Immunomediate, Istituto Superiore di Sanità,

Viale Regina Elena 299, 00161 Rome, Italy the auranofin-trypanothione reductase-NADPH complex was solved at $3.5 \AA$ resolution. In spite of the rather low resolution, these data were of sufficient quality as to identify the presence of the gold center and of the thiosugar of auranofin, and to locate them within the overall protein structure. Gold binds to the two active site cysteine residues of TR, i.e. Cys52 and Cys57, while the thiosugar moiety of auranofin binds to the trypanothione binding site; thus auranofin appears to inhibit TR through a dual mechanism. Auranofin kills the promastigote stage of L. infantum at micromolar concentration; these findings will contribute to the design of new drugs against leishmaniasis.

Keywords Gold · Auranofin - Leishmania .

Trypanothione reductase

$\begin{array}{ll}\text { Abbreviations } \\ \text { AF } & \text { Auranofin } \\ \text { CTPAu } & \text { Chloro(triethylphosphine)gold(I) } \\ \text { GR } & \text { Glutathione reductase } \\ \text { HEPES } & \begin{array}{l}\text { 4-(2-hydroxyethyl)-1-piperazineethanesulfonic } \\ \text { acid }\end{array} \\ \text { MTT } & \begin{array}{l}\text { 3-[4.5-dimethylthiazol-2-yl]-2.5- } \\ \text { diphenyltetrazolium bromide }\end{array} \\ \text { NADH } & \text { Reduced nicotinamide adenine dinucleotide } \\ \text { NADPH } & \begin{array}{l}\text { Reduced nicotinamide adenine dinucleotide } \\ \text { phosphate }\end{array} \\ \text { ROS } & \begin{array}{l}\text { Reactive oxygen species } \\ \text { Trypanothione reductase }\end{array} \\ \text { TrxR } & \begin{array}{l}\text { Thioredoxin reductase } \\ \text { TryS }\end{array} \\ \text { TS } \\ \text { Trypanothione synthatase } \\ \text { T(SH) }\end{array}$




\section{Introduction}

Leishmania parasites depend on spermidine for growth and survival. They synthesize polyamines and polyamine precursors, and also scavenge them from their microenvironment, using specific transporters. In addition, Leishmania spp. possess a unique thiol-based, polyamine-based metabolism, in which trypanothione (N1-N8-bis(glutathionyl)spermidine, $\mathrm{T}(\mathrm{SH})_{2}$ ) and trypanothione reductase (TR) replace many of the antioxidant and metabolic functions of the glutathione/glutathione reductase (GR) and thioredoxin/thioredoxin reductase (TrxR) systems present in the host (Colotti and Ilari 2011; Cunningham and Fairlamb 1995; Fairlamb et al. 1985).

Consequently, the enzymes involved in spermidine synthesis and its utilization, i.e. arginase, ornithine decarboxylase, S-adenosylmethionine decarboxylase, spermidine synthase, tryparedoxins, tryparedoxin-dependent peroxidases and, in particular, trypanothione synthetase (TryS) and TR, are targets for drug development (Colotti and Ilari 2011).

TryS and TR are necessary for Leishmania survival, protecting the parasite from oxidative damage and toxic heavy metals, and allowing the delivery of the reducing equivalents for DNA synthesis. The known sensitivity of Leishmania toward reactive oxygen species (ROS) and the absence of the trypanothione/TR system in the mammalian host make TryS and TR promising targets for the development of parasite-specific drugs.

$\mathrm{TR}$, as most enzymes involved in the polyamine metabolism in Leishmania, contains cysteine residues in the active site, and can be inhibited by metal-containing compounds. For instance, antimonial drugs, which are used against leishmaniasis since 1940s (Goodwin and Page 1943), although suffering from high toxicity and increasing resistance, interfere in vivo with the $\mathrm{T}(\mathrm{SH})_{2}$ metabolism by inducing rapid efflux of intracellular $\mathrm{T}(\mathrm{SH})_{2}$, and inhibit TR in intact cells (Cunningham and Fairlamb 1995). We disclosed the molecular mechanism of antimonial inhibition of TR by structural analysis of reduced TR in complex with reduced nicotinamide adenine dinucleotide phosphate (NADPH) and Sb(III) (Baiocco et al. 2009a). This structure revealed that the two redox-active catalytic cysteine residues (Cys52 and Cys57), one threonine residue (Thr335) and His461' of the twofold symmetry related subunit in the dimer are engaged in complex formation with $\mathrm{Sb}(\mathrm{III})$. Other metal compounds, such as silver, palladium and platinum derivatives, were reported to inhibit TR (Baiocco et al. 2011; Bonse et al. 2000; Otero et al. 2006).

Auranofin (AF) is a gold complex largely used in the clinics as an antiarthritic drug. It consists of a gold(I) center linearly coordinated to triethylphosphine and to $3,4,5$
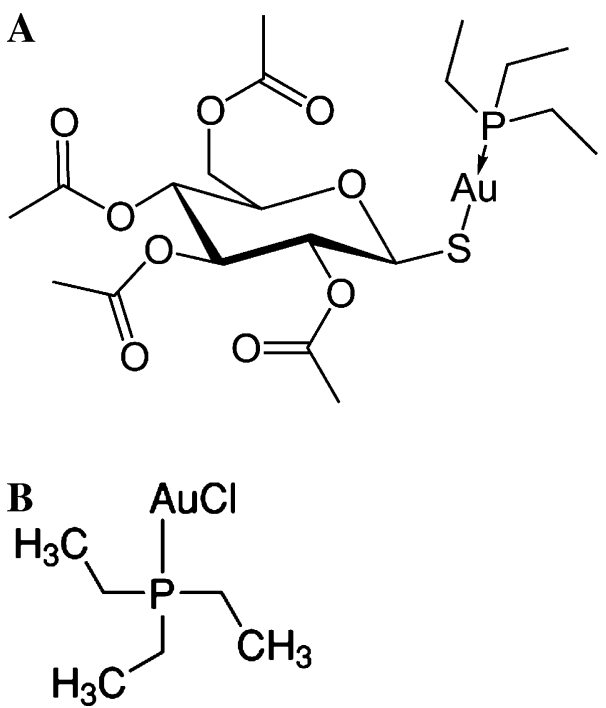

Fig. 1 a Chemical structure of auranofin (AF); b chemical structure of Chloro(triethylphosphine)gold(I) (CTPAu)

triacetyloxy-6-(acetyloxymethyl)oxane-2-thiolate, a thiosugar (Fig. 1). Detachment of the latter results into drug activation. Quite recently, a few studies revealed that auranofin might be conveniently employed for a number of different therapeutic indications (Fonteh et al. 2010; Kast 2010; Kean and Kean 2008; Navarro et al. 2010; PrastNielsen et al. 2010). In particular, it was shown that the gold(I) center of AF, being markedly thiophilic, manifests a high affinity for dithiol motifs, often present in the active site of some crucial parasitic enzymes. In view of this property it was proposed that auranofin might be tested as an antiparasitic agent.

Since AF induces strong inhibition of parasite growth for Plasmodium falciparum and for Schistosoma mansoni through the inhibition of thiol-dependent redox enzymes such as thioredoxin reductase and thioredoxin glutathione reductase (Angelucci et al. 2009; Kuntz et al. 2007; Sannella et al. 2008), we decided to explore whether AF might be used as an antileishmanial agent, in in vitro tests of growth inhibition of promastigotes from $L$. infantum and L. major species.

To corroborate these hypotheses, auranofin was challenged in vitro against trypanothione reductase, an important target of Leishmania, essential for trypanosomatids, to test its ability of inhibiting the enzyme. We also obtained crystal reduced TR from $L$. infantum in complex with NADPH and AF, thus demonstrating the mechanism of TR inhibition by gold derivatives.

In addition, since compounds such as gold(I) triphenylphosphine have a potent antiproliferative effect on Leishmania spp. and Trypanosoma cruzi, due to the reduced nicotinamide adenine dinucleotide (NADH) fumarate 
reductase inhibition (Vieites et al. 2009), we measured the ability of Chloro(triethylphosphine)gold(I) (CTPAu), i.e. a very soluble variant of AF (Fig. 1), which lacks the thiosugar moiety, to inhibit TR.

\section{Methods}

TR inhibition assay

TR activity was measured at $25^{\circ} \mathrm{C}$ in a diode array HewlettPackard HP8452A spectrophotometer as previously described (Baiocco et al. 2009a). Experiments for calculation of the $K$ i values were carried out by varying $\mathrm{AF}$ and CTPAu concentration. In a cuvette, $40 \mathrm{mM}$ 4-(2hydroxyethyl)-1-piperazineethanesulfonic acid (HEPES) $\mathrm{pH} 7.5,50 \mathrm{mM} \mathrm{NaCl}, 100 \mu \mathrm{M}$ NADPH, $40 \mathrm{nM}$ TR and the gold derivatives were allowed to equilibrate for $2 \mathrm{~min}$ at $25^{\circ} \mathrm{C}$ immediately prior the addition of trypanothione disulfide $\left(\mathrm{TS}_{2}\right)$. Assays were initiated by addition of $\mathrm{TS}_{2}$ and the absorbance decrease at $340 \mathrm{~nm}$, which indicates the oxidation of NADPH, was followed. The concentrations of NADPH was calculated using the extinction coefficient of a $\varepsilon=6,222 \mathrm{M}^{-1} \mathrm{~cm}^{-1}$ at $340 \mathrm{~nm}$. Trypanothione disulfide (Bachem) and NADPH (Sigma) were used for the experiments. Auranofin was purchased from Vinci Biochem and CTPAu from Sigma Chemical Company.

\section{X-ray structure determination}

Crystallization of TR from Leishmania infantum was carried out as reported previously (Baiocco et al. 2009b).

Crystals of the native oxidized form of TR were soaked for $1 \mathrm{~h}$ with a stabilizing solution of $2.5 \mathrm{M}$ ammonium sulfate, $0.1 \mathrm{M}$ Tris $\mathrm{pH} 8.5$ containing $2 \mathrm{mM} \mathrm{AF}$ and $5 \mathrm{mM}$ NADPH. Crystals were cryo-protected in a solution containing $75 \% \mathrm{v} / \mathrm{v}$ of the reservoir solution and $25 \% \mathrm{v} / \mathrm{v}$ of glycerol.

Single wavelength data set $(\lambda=0.918 \AA)$ was collected at the beamline ID 14-1 at the synchrotron radiation source ESRF in Grenoble, France, using a CCD detector at a temperature of $100 \mathrm{~K}$.

The data set was processed with DENZO (Otwinowski and Minor 1997) and scaled with SCALEPACK (Otwinowski and Minor 1997). The crystals belong to the $\mathrm{P} 41$ space group with the following cell dimensions: $a=103.05 \AA, b=103.05 \AA$, $c=191.6 \AA$ A. Crystal parameters and complete data collection statistics are given in Table 1.

The structure of $L$. infantum TR in complex with AF and NADPH was solved by molecular replacement using as search model the native TR (pdb code 2JK6) with the program Molrep (Vagin and Teplyakov 1997). Refinement was performed using the program REFMAC5 (Murshudov
Table 1 Crystal parameters, data collection and refinement statistics

\begin{tabular}{|c|c|}
\hline \multicolumn{2}{|l|}{ Data collection } \\
\hline Space group & $\mathrm{P} 4_{1}$ \\
\hline Unit cell dimension $(\AA)$ & $\begin{array}{c}a=103.58, b=103.58 \\
c=191.60\end{array}$ \\
\hline Resolution range $(\AA)$ & $50-3.50(3.63-3.5)$ \\
\hline Total reflections & 164492 \\
\hline Unique reflections & 25665 \\
\hline Completeness $(\%)$ & $100(100)$ \\
\hline$R_{\text {merge }}$ & $0.17(0.50)$ \\
\hline Redundancy & $6.4(6.4)$ \\
\hline$<I / \sigma(I)>$ & $9.4(1.9)$ \\
\hline \multicolumn{2}{|l|}{ Refinement statistics } \\
\hline Resolution range $(\AA)$ & $50.0-3.5(3.59-3.50)$ \\
\hline Free $R$ value $(\%)$ & $31.9(41.3)$ \\
\hline$R$ value (working set) $(\%)$ & $26.7(39.7)$ \\
\hline RMS bonds $(\AA)$ & 0.009 \\
\hline RMS angles $\left({ }^{\circ}\right)$ & 1.24 \\
\hline \multicolumn{2}{|l|}{ Ramachandran analysis } \\
\hline Residues in most favoured regions (\%) & 92.2 \\
\hline Residues in allowed regions (\%) & 7.1 \\
\hline Outliers (\%) & 0.7 \\
\hline
\end{tabular}

Values in parentheses are for the highest resolution shell

$R_{\text {merge }}=\Sigma_{h k l} \Sigma_{i}\left|\mathrm{I}_{i}(h k l)-<I(h k l)>\right| / \Sigma_{h k l} \Sigma_{i} \mathrm{I}_{i}(h k l)$ where $I_{i}(h k l)$ is the $i$ th observation of the reflection $(h k l)$ and $\langle I(h k l)\rangle$ is the mean intensity of the $(h k l)$ reflection

et al. 1997) and model building was carried out using the program COOT (Emsley and Cowtan 2004). The final $R_{\text {crys }}$ for all resolution shells (50-3.5 $\AA$ ), calculated using the working set reflections (22593), is $26.7 \%$ and the free $R$ value, calculated using the test set reflections (1291), is $31.9 \%$. The final model is a dimer that contains 976 residues (488 for monomer A and 488 for monomer B), two FAD molecules, two NADPH molecules, two gold ions, two chloride ions, two (3,4,5 triacetyloxy-6-(acetyloxymethyl) oxane-2-thiolate thiosugars, and two sulphate ions (Schuettelkopf and van Aalten 2004). The most favored regions of the Ramachandran plot contain $92.2 \%$ of residues. The atomic coordinates and structure factors have been deposited in the Protein Data Bank with the PDB code 2YAU.

Parasite strains and promastigote assays

Promastigote stage of L. infantum strain MHOM/TN/80/ IPT1 and L. major strain MHOM/SU/73/5-ASKH were used in drug susceptibility assays. Promastigotes were grown in Schneider's Drosophila medium (SIGMA) containing 10\% Fetal Calf Serum (FCS) (GIBCO-BRL) and $2 \%$ gentamicine $(50 \mathrm{mg} / \mathrm{L})(\mathrm{Sigma})$ at $22^{\circ} \mathrm{C}$. The effect on 

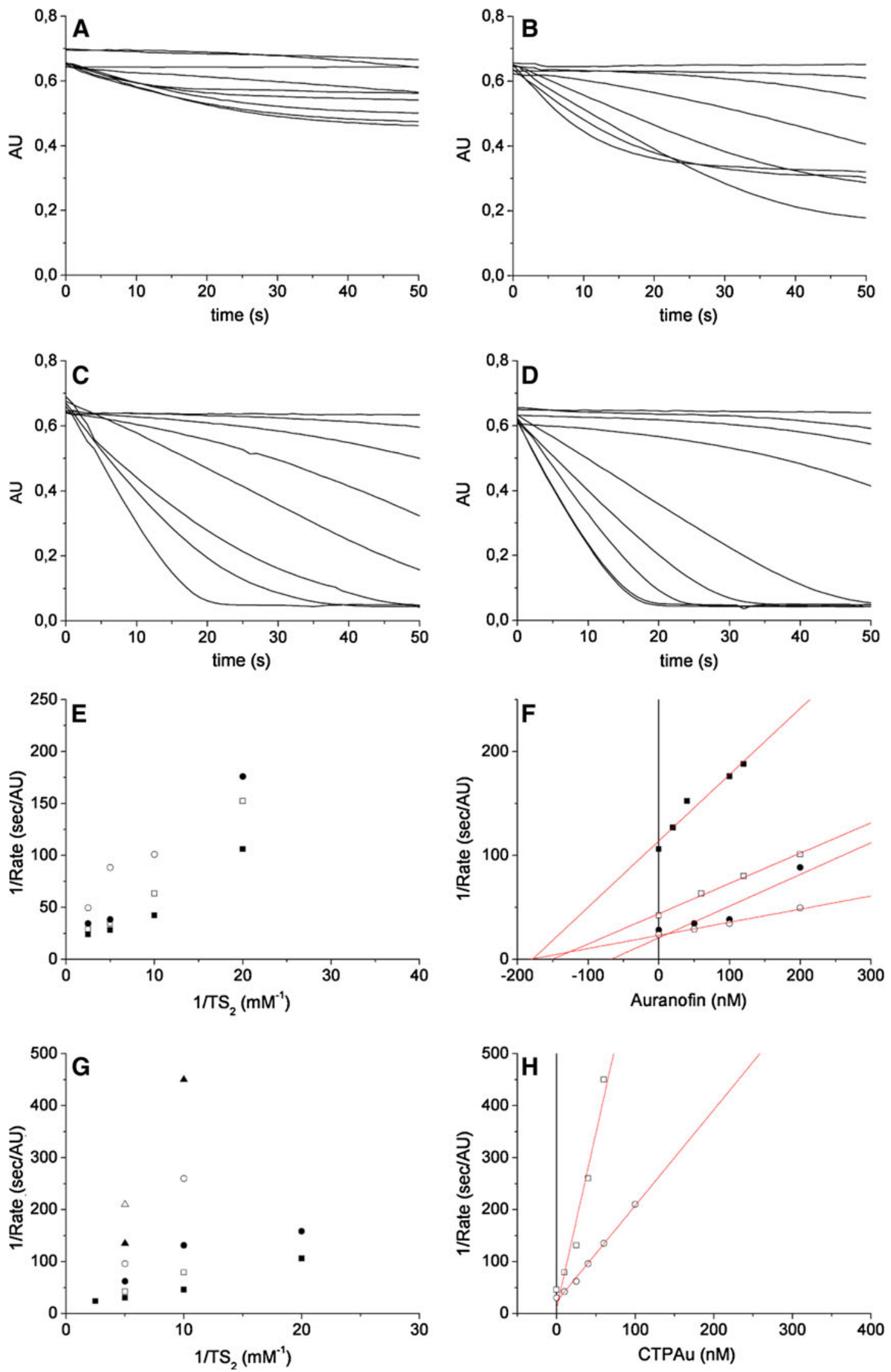
4 Fig. 2 Inhibition of TR by AF and CTPAu. a-d Oxidation kinetics of NADPH $(100 \mu \mathrm{M})$ in the presence of $40 \mathrm{nM}$ TR and of different concentrations of $\mathrm{AF}$ and $\mathrm{TS}_{2}$, measured at $340 \mathrm{~nm}$. $\left[\mathrm{TS}_{2}\right]$ a $50 \mu \mathrm{M}$; b $100 \mu \mathrm{M} ; \mathbf{c} 200 \mu \mathrm{M} ; \mathbf{d} 400 \mu \mathrm{M}$. [AF] traces in a 0, 20, 40, 100, 120, $250,500 \mathrm{nM}, 1,5 \mu \mathrm{M}$; traces in b $0,50,120,200,500 \mathrm{nM}, 1,2$, $10 \mu \mathrm{M}$; traces in $\mathbf{c} 0,50,100,200,500 \mathrm{nM}, 1,2,10 \mu \mathrm{M}$; traces in $\mathbf{d}$ : $0,50,100,200,400 \mathrm{nM}, 1,2,5,10 \mu \mathrm{M}$. e Lineweaver-Burk plot and f Dixon plot of TR inhibition by auranofin. e filled squares $[\mathrm{AF}]=0$; open squares $[\mathrm{AF}]=50 \mathrm{nM}$; filled circles $[\mathrm{AF}]=100 \mathrm{nM}$; open circles $[\mathrm{AF}]=200 \mathrm{nM}$. f filled squares $\left[\mathrm{TS}_{2}\right]=50 \mu \mathrm{M}$; open squares $\left[\mathrm{TS}_{2}\right]=100 \mu \mathrm{M}$; filled circles $\left[\mathrm{TS}_{2}\right]=200 \mu \mathrm{M}$; open circles $\left[\mathrm{TS}_{2}\right]=400 \mu \mathrm{M}$. g Lineweaver-Burk plot and $\mathbf{h}$ Dixon plot of TR inhibition by CTPAu. $\mathbf{g}$ filled squares $[\mathrm{CTPAu}]=0$; open squares $[\mathrm{CTPAu}]=10 \mathrm{nM} ;$ filled circles $[\mathrm{CTPAu}]=25 \mathrm{nM} ;$ open circles $[\mathrm{CTPAu}]=40 \mathrm{nM}$; filled triangles $[\mathrm{CTPAu}]=60 \mathrm{nM}$; open triangles $[\mathrm{CTPAu}]=100 \mu \mathrm{M}$. h open squares $\left[\mathrm{TS}_{2}\right]=100 \mu \mathrm{M}$; open circles $\left[\mathrm{TS}_{2}\right]=200 \mu \mathrm{M}$

cell growth was analyzed incubating an initial concentration of $1 \times 10^{6}$ parasites $/ \mathrm{mL}$ with various concentrations of the compounds.

Briefly, a $200 \mu \mathrm{L}$ volume of suspension was seeded in triplicate in 96-well flat-bottom microtrays and incubated with different concentration of two gold compounds (AF and CTPAu): 50, 40, 30, 25, 20, 15, 10, 7.5, 5, 2.5, $1.25 \mu \mathrm{M}$. Antimonial compound was used as the reference anti-Leishmania drug. Each experiment was carried out in triplicate for each concentration. After $72 \mathrm{~h}$ of incubation, $40 \mu \mathrm{L}$ of MTT (3-[4.5-dimethylthiazol-2-yl]-2.5-diphenyltetrazolium bromide) was added to each well and plates were further incubated for $2 \mathrm{~h}$. The absorbance at $490 \mathrm{~nm}$ was measured with a 96-well scanner. Two independent experiments in triplicate were performed. In addition, the promastigote vitality was followed by microscopic observation after $72 \mathrm{~h}$. Dose-response curves were recorded and the $50 \%$ inhibitory concentration $\left(\mathrm{IC}_{50}\right)$ values were determined by GraphPad Prism 5.

\section{Results}

At first, we explored whether AF might behave as an inhibitor of TR. Steady state condition kinetic experiments were carried out at various concentration of $\mathrm{TS}_{2}$ and inhibitor. After starting the reaction by the addition of $\mathrm{TS}_{2}$, the absorbance decrease at $340 \mathrm{~nm}$, which indicates the oxidation of NADPH, was measured. Although a few traces (Fig. 2a, b) show a complex behavior, possibly due to auranofin modification, AF has a clear inhibitory effect on TR. Addition of increasing amount of AF resulted into remarkable enzyme inhibition, with a $K_{\mathrm{i}}$ value of $155 \pm 35 \mathrm{nM}$, about 10 times lower than $\mathrm{Sb}$ (III) (Baiocco et al. 2009a), in the conditions tested (Fig. 2). CTPAu has a even higher inhibitory activity on TR, with a $K_{\mathrm{i}}$ of $18 \pm 7$ nM (Fig. 2).

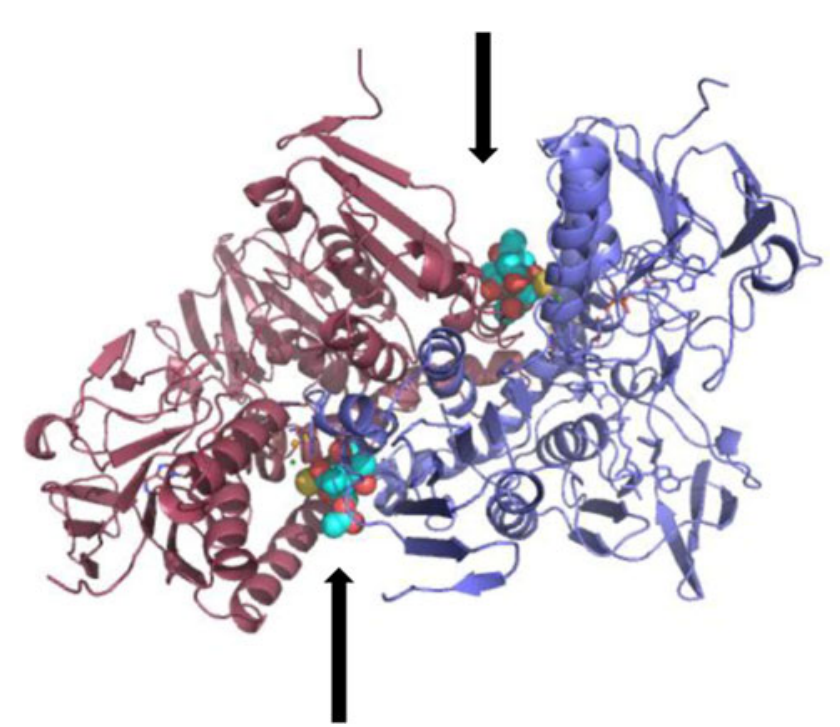

Fig. 3 X-ray structure of the $\mathrm{Au}(\mathrm{I})$-TR complex A. Overall structure. The two subunits in the asymmetric unit are colored in red and in blue, respectively. The trypanothione binding cavities are indicated by arrows and the thiosugar moiety is indicated in CPK. The picture is generated in PyMol (DeLano 2008)

To unveil the structural basis of enzyme inhibition, we tried to prepare crystals of the AF-inhibited enzyme that could be suitable for X-ray diffraction analysis. Several attempts were made based on co-crystallization, but all of these failed, since no crystals of crystallographic quality were obtained. Crystals of reduced TR in complex with NADPH and AF of reasonable crystallographic quality were in turn obtained by soaking crystals of oxidized TR for $1 \mathrm{~h}$ with a stabilizing solution of $2.5 \mathrm{M}$ ammonium sulfate, $0.1 \mathrm{M}$ Tris $\mathrm{pH} 8.5$ containing $2 \mathrm{mM} \mathrm{AF}$ and $5 \mathrm{mM}$ NADPH. These crystals were used to solve the structure TR in complex with $\mathrm{AF}$ at $3.5 \AA$ resolution.

In spite of the fact that the resolution is rather low, diffraction data were sufficient to delineate the overall protein structure, which is practically superposable (RMSD about $0.5 \AA$ ) to those obtained for the $\mathrm{Sb}$ (III)-bound and the silver-bound TR structures (Baiocco et al. 2009a, 2011) (Fig. 3). A very clear electron density in the Fo-Fc map was found in both subunits, accounting for the presence of gold ions nearby the catalytic site, namely Cys52, Cys57 and His461' with an occupancy of $40 \%$ for both subunits (Fig. 4a).

In addition, the inspection of the electronic density map allowed us to identify the thiosugar moiety of AF in the active site of TR with an occupancy of $70 \%$ (Fig. 4b). The Fo-Fc electronic density map contoured at $3.0 \AA$ indicates the presence of an additional conformation with low occupancy.

As shown in the Fig. $4 \mathrm{a}, \mathrm{Au}(\mathrm{I})$ is coordinated by three ligands. The two cysteine residues of the active site (Cys52 

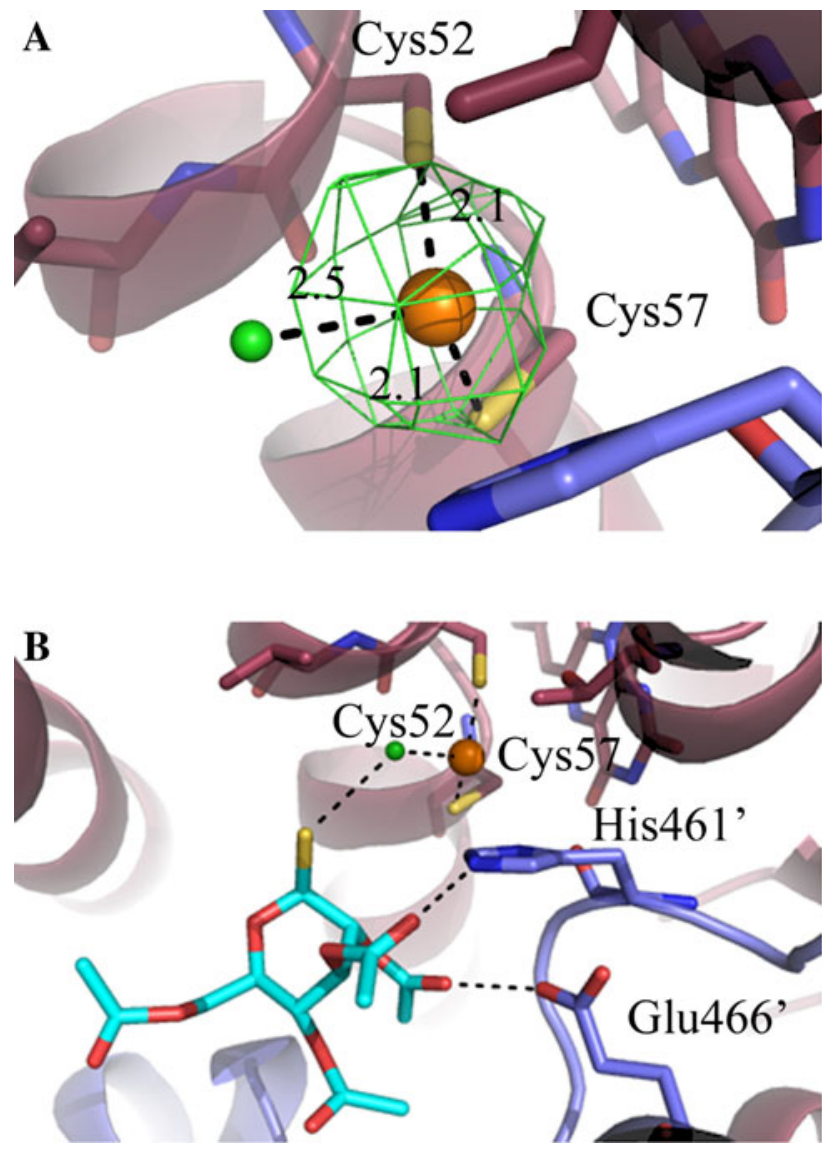

Fig. 4 a $A u(I)$ binding site. The gold and the chloride ions are indicated in orange and green, respectively. The anomalous difference Fourier map for data collected at the gold peak wavelength is shown at a $5 \sigma$ contour level in green. b Trypanothione binding site. The Cys52, Cys57, Thr335, His461', Glu466' residues, the FAD molecule and the thiosugar moiety are represented as sticks. The pictures have been generated in PyMol (DeLano 2008)

and Cys57), are bound to the $\mathrm{Au}(\mathrm{I})$ ion with distances $\mathrm{SG}_{\mathrm{Cys} 52}-\mathrm{Au}=2.1 \AA$ and $\mathrm{SG}_{\mathrm{Cys} 57}-\mathrm{Au}=2.1 \AA$, respectively. The third ligand is a chloride ion, placed at a distance of $2.5 \AA$ from $\mathrm{Au}(\mathrm{I})$. Thus, in the auranofin-TR complex the gold ion displays a planar-trigonal coordination, where the ligands are the two cysteine residues and a chloride ion, one of the principal coordination geometries of the $\mathrm{d}^{10}$ closed-shell-configuration $\mathrm{Au}(\mathrm{I})$ (Shaw 1999).

The 3,4,5-triacetyloxy-6-(acetyloxymethyl)oxane-2thiolate thiosugar is bound at the trypanothione binding site, and forms contacts with the chloride ion and with two important residues of TR, His461' and Glu466', belonging to the second subunit of the dimer, which activate Cys52 similarly to serine and cysteine proteases during trypanothione reduction (Fig. 4b). The distance between the sulphur atom of the thiosugar and the chloride is $3.1 \AA$, while the acetate groups of the thiosugar are at distances of about $3 \AA$ from His $461^{\prime}$, Glu466' and Glu467'. In particular, the oxygen atoms of the acetate groups are $2.9 \AA$ away from
Table 2 Activity of auranofin and CTPAu against Leishmania parasites

\begin{tabular}{lrl}
\hline Compounds & \multicolumn{1}{c}{ L. infantum } & \multicolumn{1}{l}{ L. major } \\
\hline Auranofin & $9.68 \pm 1.02$ & $15.66 \pm 1.24$ \\
CTPAu & $16.59 \pm 1.03$ & $17.48 \pm 1.02$ \\
\hline
\end{tabular}

Results are expressed as $\mathrm{IC}_{50}(\mu \mathrm{M}) \pm$ standard error

the nitrogen NE2 of His $461^{\prime}, 3.1 \AA$ apart from the carboxyl group of Glu $466^{\prime}$, and at $3.3 \AA$ from the carboxyl group of Glu467'. Therefore, AF blocks the two cysteine residues of the active site, and does not allow binding of trypanothione to His $461^{\prime}$, belonging to the catalytic triad of TR, and to Glu466', which stabilizes the His $461^{\prime}$ positive charge during the redox reaction catalysed by TR.

The possible use of $\mathrm{AF}$ as antileishmanial drug was tested by promastigote growth inhibition assays.

Both AF and CTPAu induced a dose-dependent antiproliferative effect on promastigotes, the extracellular Leishmania stage of both L. infantum and L. major species. A dose of $50 \mu \mathrm{M}$ of either gold compounds induced $100 \%$ promastigote mortality, whereas concentrations $<40 \mu \mathrm{M}$ determined a leishmanistatic activity, with different rates of inhibition activity of two Leishmania species. At these sub-lethal concentrations, parasites showed motility inhibition and body swelling, not present in control cells. Lower concentrations, $\leq 2.5 \mu \mathrm{M}$, did not affect either promastigote growth or morphology. The $\mathrm{IC}_{50}$ values deduced from the dose-response curve are different for the two compounds (Table 2). AF produced a higher leishmanistatic activity than CTPAu against both Leishmania species. Indeed, the auranofin $\mathrm{IC}_{50}$ was $9.68 \pm 1.02 \mu \mathrm{M}$ for $L$. infantum and $15.66 \pm 1.24 \mu \mathrm{M}$ for $L$. major, whereas the CTPAu $\mathrm{IC}_{50}$ showed slightly higher values, i.e. $16.59 \pm 1.03 \mu \mathrm{M}$ for $L$. infantum and $17.48 \pm 1.02 \mu \mathrm{M}$ for L. major.

\section{Discussion}

The experiments presented in the present work show that auranofin, a drug used against rheumatoid arthritis, is able to inhibit with a dual mechanism the trypanothione reductase, a key enzymes of the polyamine metabolism in Leishmania, thereby killing the Leishmania parasites.

The available treatments for leishmaniasis are far from ideal. The traditional first-line treatment relies on pentavalent antimonials. Amphotericin B, the aromatic diamidine pentamidine and, more recently, miltefosine, are often effective, though they also have severe side effects.

With the exception of antimonials, the use of metalcontaining drugs as antileishmanial agents has not been deeply explored up to now, although the emergence of 
drug-resistant strains of Leishmania warrants screening of new compounds and rational drug design.

Metals are often considered not selective. However, a few studies show promising results against the parasite. For example, zinc sulfate was tested clinically against cutaneous leishmaniasis, with cure rates $>96.0 \%$ (Minodier and Parola 2007). Platinum-based DNA intercalators inhibit growth of Leishmania parasites (Lowe et al. 1999; Visbal et al. 2008), also displaying inhibitory activity versus metabolically important enzymes. A gold(I)-based complex with the bioactive coligand pyridine-2-thiol $\mathrm{N}$-oxide shows inhibition of NADH fumarate reductase, a kinetoplastid parasite-specific enzyme absent in the host (Visbal et al., 2008), while gold(III) derivatives as $\left[\mathrm{Au}(\mathrm{dppz})_{2}\right] \mathrm{Cl}_{3}$ and $\mathrm{Au}(\mathrm{III})$ cyclometallated complexes are DNA intercalators with antileishmanial activity, the latter inhibiting different cysteine proteases in Trypanosoma and Leishmania (Fricker et al. 2008; Navarro et al. 2007).

These results prompted us to study the possibility of using AF, a gold(I)-containing drug, with known pharmacokinetics and pharmacodynamics, against leishmaniasis.

Auranofin (Ridaura), gold sodium thiomalate and aurothioglucose (Solganal) are gold-containing chemicals used in treating rheumatoid arthritis. In patients with inflammatory arthritis, such as adult and juvenile rheumatoid arthritis, gold salts decrease the inflammation of the joint lining and also prevent the inflammation from destroying the bone and cartilage surrounding the joint. Because they prevent destruction of joints (in contrast to antiinflammatory drugs that just treat symptoms and signs of arthritis but do not prevent the destruction) AF is known as a diseasemodifying antirheumatic drug (DMARD) (Rau 2005). Chrysotherapy is also considered for cancer (Marzano et al. 2007; Shaw 1999).

The mechanism of action of AF is not fully known; gold is taken up by macrophages, which results in inhibition of phagocytosis and lysosomal membrane stabilization; other actions observed are decreased serum rheumatoid factor and alterations in immunoglobulins. Additionally, complement activation is decreased, prostaglandin synthesis is inhibited, and lysosomal enzyme activity is decreased (Bondeson 1997; Haynes et al. 1988).

In addition, $\mathrm{AF}$ and other gold-containing drugs are strong inhibitors of protozoan thioredoxin glutathione reductase and of mammalian thioredoxin reductases (Gromer et al. 1998; Kuntz et al. 2007). Notably, inhibition of these reductases is associated with important modifications of the intracellular redox balance and, in particular, with induction of severe oxidative stress and relevant cytotoxic effects in vitro ( $\mathrm{Lu}$ et al. 2007; Yoo et al. 2006).

Since Leishmania effectively avoids the humoral branch of the host immune system by infecting preferentially the macrophage as amastigote, the preferential uptake of AF by the macrophages is of particular importance for treatment of leishmaniases, and should make the drug more effective and specific against the parasite.

AF inhibits TR from $L$. infantum with a $K_{\mathrm{i}}$ of $155 \pm 35 \mathrm{nM}$, while the inhibition constant measured for $\mathrm{Sb}$ (III) is $1.5 \mu \mathrm{M}$ : another gold(I) derivative, CTPAu, a very soluble variant of AF, lacking its thiosugar moiety, inhibits TR with a $K_{\mathrm{i}}$ of $18 \pm 7 \mathrm{nM}$. Therefore, Au(I)containing drugs are more effective than antimony in vitro. Recently, inhibition constants for $\operatorname{Ag}(0)$ and $\operatorname{Ag}(\mathrm{I})$ of 500 and $50 \mathrm{nM}$, respectively, were measured on TR (Baiocco et al. 2011). Therefore, $\mathrm{Au}(\mathrm{I})$-containing compounds are very effective TR inhibitors.

The structural analysis of the crystal of reduced L. infantum TR in complex with NADPH and AF, solved at $3.5 \AA$ resolution, demonstrates that the mechanism of inhibition is only partly similar to that of $\mathrm{Sb}$ (III). In fact the structure inspection clearly show that upon TR reduction by NADPH, Au(I) binds to the two cysteines Cys52 and Cys57 with a planar triangular coordination involving also a chloride ion, while both $\mathrm{Sb}$ (III) and silver bind the three residues of the catalytic triad (Cys52, Cys57 and His461') of the enzyme.

In addition, although the relatively low resolution of the structure impairs a deeper analysis, the 3,4,5-triacetyloxy6-(acetyloxymethyl)oxane-2-thiolate thiosugar of AF clearly occupies the trypanothione binding site, thus impairing substrate binding and engaging in hydrogen bond interactions both His461' and Glu466', that are involved in Cys52 activation during catalysis (Baiocco et al. 2009a; Karplus and Schulz 1989). AF therefore inhibits TR with a dual mechanism, i.e. by blocking both binding and reduction of oxidized trypanothione by TR.

These results are confirmed by in vitro experiments on L. infantum promastigotes, which showed that AF is able to kill the parasite at micromolar concentrations.

For these reasons, the authors believe that the use of gold-containing compounds represents a reasonable approach for the optimization of therapeutic strategies against leishmaniasis.

\section{Conclusions}

In the structures of TR in complex with NADPH and AF, as for those with $\mathrm{Sb}$ (III) or silver (Baiocco et al. 2009a, 2011), the metal ion is tightly bound to two cysteine groups in the active site of the enzyme, thereby disallowing the hydride transfer from the protein to the trypanothione. In addition, the thiosugar of auranofin contributes to TR inhibition by occupying the trypanothione binding site of TR.

This finding, and the works reporting that, in addition to gold derivatives, also silver, palladium and platinum 
derivatives, were reported to inhibit TR (Baiocco et al. 2011; Bonse et al. 2000; Otero et al. 2006), suggest that thiophilic metals that are Lewis soft acids, more generally, may serve as strong inhibitors of TR and may result in potential interest as antileishmanial agents.

The structural studies were independently supported by enzyme inhibition data for AF and CTPAu.

Such metal-dependent inhibition of thiol reductases opens the way to combined metal therapy of leishmaniasis. In view of these results we can state that AF behaves as a relatively strong inhibitor of TR and is endowed of antileishmanial activity in the micromolar range of concentration.

Studies are in progress to evaluate comparative enzyme inhibition by a series of structurally different gold complexes.

Acknowledgments We acknowledge the European Synchrotron Radiation Facility (Grenoble, France) for provision of synchrotron radiation at beamline ID 14-1 and PRIN2007 to GC. We thank Dr. Francesco Angelucci and Dr. Veronica Morea for useful comments.

\section{References}

Angelucci F, Sayed AA, Williams DL, Boumis G, Brunori M, Dimastrogiovanni D, Miele AE, Pauly F, Bellelli A (2009) Inhibition of Schistosoma mansoni thioredoxin-glutathione reductase by auranofin: structural and kinetic aspects. J Biol Chem 284(42):28977-28985

Baiocco P, Colotti G, Franceschini S, Ilari A (2009a) Molecular basis of antimony treatment in leishmaniasis. $\mathrm{J}$ Med Chem 52:2603-2612

Baiocco P, Franceschini S, Ilari A, Colotti G (2009b) Trypanothione reductase from Leishmania infantum: cloning, expression, purification, crystallization and preliminary X-ray data analysis. Protein Peptide Lett 16(2):196-200

Baiocco P, Ilari A, Ceci P, Orsini S, Gramiccia M, Di Muccio T, Colotti G (2011) Inhibitory effect of silver nanoparticles on trypanothione reductase activity and Leishmania infantum proliferation. ACS Med Chem Lett 2(3):230-233

Bondeson J (1997) The mechanisms of action of disease-modifying antirheumatic drugs: a review with emphasis on macrophage signal transduction and the induction of proinflammatory cytokines. Gen Pharmacol 29(2):127-150

Bonse S, Richards JM, Ross SA, Lowe G, Krauth-Siegel RL (2000) $\left(2,2^{\prime}: 6\right.$ ',2"-Terpyridine)platinum(II) complexes are irreversible inhibitors of Trypanosoma cruzi trypanothione reductase but not of human glutathione reductase. J Med Chem 43:4812-4821

Colotti G, Ilari A (2011) Polyamine metabolism in Leishmania: from arginine to trypanothione. Amino Acids 40(2):269-285

Cunningham ML, Fairlamb AH (1995) Trypanothione reductase from Leishmania donovani. Purification, characterisation and inhibition by trivalent antimonials. Eur J Biochem 230:460-468

DeLano WL (2008) The PyMOL molecular graphics system. DeLano Scientific LLC, Palo Alto

Emsley P, Cowtan K (2004) Coot: model-building tools for molecular graphics. Acta Crystallogr D Biol Crystallogr 60:2126-2132

Fairlamb AH, Blackburn P, Ulrich P, Chait BT, Cerami A (1985) Trypanothione: a novel bis(glutathionyl)spermidine cofactor for glutathione reductase in trypanosomatids. Science 227:14851487
Fonteh PN, Keter FK, Meyer D (2010) HIV therapeutic possibilities of gold compounds. Biometals 23(2):185-196

Fricker SP, Mosi RM, Cameron BR, Baird I, Zhu Y, Anastassov V, Cox J, Doyle PS, Hansell E, Lau G, Langille J, Olsen M, Qin L, Skerlj R, Wong RS, Santucci Z, McKerrow JH (2008) Metal compounds for the treatment of parasitic diseases. J Inorg Biochem 102(10):1839-1845

Goodwin LG, Page JE (1943) A study of the excretion of organic antimonials using a polarographic procedure. Biochem $\mathrm{J}$ 22:236-240

Gromer S, Arscott LD, Williams CH Jr, Schirmer RH, Becker K (1998) Human placenta thioredoxin reductase. Isolation of the selenoenzyme, steady state kinetics, and inhibition by therapeutic gold compounds. J Biol Chem 273:20096-20101

Haynes DR, Garrett IR, Vernon-Roberts B (1988) Effect of gold salt treatment on the receptor binding activity of monocytes and macrophages isolated from rats with adjuvant arthritis. Rheumatol Int 8(4):159-164

Karplus PA, Schulz GE (1989) Substrate binding and catalysis by glutathione reductase as derived from refined enzyme: substrate crystal structures at $2 \AA$ resolution. J Mol Biol 210:163-180

Kast RE (2010) Glioblastoma invasion, cathepsin B, and the potential for both to be inhibited by auranofin, an old anti-rheumatoid arthritis drug. Cent Eur Neurosurg 71(3):139-142

Kean WF, Kean IR (2008) Clinical pharmacology of gold. Inflammopharmacol 16(3):112-125

Kuntz AN, Davioud-Charvet E, Sayed AA, Califf LL, Dessolin J, Arnér ES, Williams DL (2007) Thioredoxin glutathione reductase from Schistosoma mansoni: an essential parasite enzyme and a key drug target. PLoS Med 4(6):e206

Lowe G, Droz AS, Vilaivan T, Weaver GW, Tweedale L, Pratt JM, Rock P, Yardley V, Croft SL (1999) Cytotoxicity of (2,2':6',2'”terpyridine)platinum(II) complexes to Leishmania donovani, Trypanosoma cruzi, and Trypanosoma brucei. J Med Chem 42:999-1006

Lu J, Chew EH, Holmgren S, Targeting A (2007) TrxR is a basis for cancer therapy by arsenic trioxide. Proc Natl Acad Sci USA 104:12288-12293

Marzano C, Gandin V, Folda A, Scutari G, Bindoli A, Rigobello MP (2007) Inhibition of thioredoxin reductase by auranofin induces apoptosis in cisplatin-resistant human ovarian cancer cells. Free Radic Biol Med 42(6):872-881

Minodier P, Parola P (2007) Cutaneous leishmaniasis treatment. Travel Med Infect Dis 5:150-158

Murshudov GN, Vagin AA, Dodson EJ (1997) Refinement of macromolecular structures by the maximum-likelihood method. Acta Crystallogr D Biol Crystallogr 53:240-255

Navarro M, Hernández C, Colmenares I, Hernández P, Fernández M, Sierraalta A, Marchán E (2007) Synthesis and characterization of [Au(dppz)2]Cl3. DNA interaction studies and biological activity against Leishmania (L.) mexicana. J Inorg Biochem 101(1): $111-116$

Navarro M, Gabbiani C, Messori L, Gambino D (2010) Metal-based drugs for malaria, trypanosomiasis and leishmaniasis: recent achievements and perspectives. Drug Discov Today 15(23-24): 1070-1078

Otero L, Vieites M, Boiani L, Denicola A, Rigol C, Opazo L, OleaAzar C, Maya JD, Morello A, Krauth-Siegel RL, Piro OE, Castellano E, Gonzalez M, Gambino D, Cerecetto H (2006) Novel antitrypanosomal agents based on palladium nitrofurylthiosemicarbazone complexes: DNA and redox metabolism as potential therapeutic targets. J Med Chem 49:3322-3331

Otwinowski Z, Minor W (1997) Processing of X-ray diffraction data collected in oscillation mode. Methods Enzymol 276:307-326

Prast-Nielsen S, Cebula M, Pader I, Arnér ES (2010) Noble metal targeting of thioredoxin reductase-covalent complexes with 
thioredoxin and thioredoxin-related protein of $14 \mathrm{kDa}$ triggered by cisplatin. Free Radic Biol Med 49(11):1765-1778

Rau R (2005) Have traditional DMARDs had their day? Effectiveness of parenteral gold compared to biologic agents. Clin Rheumatol 24:189-202

Sannella AR, Casini A, Gabbiani C, Messori L, Bilia AR, Vincieri FF, Majori G, Severini C (2008) New uses for old drugs. Auranofin, a clinically established antiarthritic metallodrug. exhibits potent antimalarial effects in vitro: mechanistic and pharmacological implications. FEBS Lett 582(6):844-847

Schuettelkopf AW, van Aalten DMF (2004) PRODRG: a tool for high-throughput crystallography of protein-ligand complexes. Acta Crystallogr D 60:1355-1363

Shaw CF (1999) Gold-based therapeutic agents. Chem Rev 99:2589-2600

Vagin A, Teplyakov A (1997) MOLREP: an automated program for molecular replacement. J Appl Cryst 30:1022-1025
Vieites M, Smircich P, Buggeri L, Marchán E, Gómez-Barrio A, Navarro M, Garat B, Gambino D (2009) Synthesis and characterization of a pyridine-2-thiol $\mathrm{N}$-oxide gold(I) complex with potent antiproliferative effect against Trypanosoma cruzi and Leishmania sp. insight into its mechanism of action. J Inorg Biochem 103:1300-1306

Visbal G, Marchán E, Maldonado A, Simoni Z, Navarro M (2008) Synthesis and characterization of platinum-sterol hydrazone complexes with biological activity against Leishmania (L.) mexicana. J Inorg Biochem 102(3):547-554

Yoo MH, Xu XM, Carlson BA, Gladyshev VN, Hatfield DL (2006) Thioredoxin reductase 1 deficiency reverses tumor phenotype and tumorigenicity of lung carcinoma cells. J Biol Chem 281:13005-13008 